\title{
Prevalence and associated factors of pre- eclampsia among pregnant women attending anti-natal care at Mettu Karl referal hospital, Ethiopia: cross-sectional study
}

\author{
Alemayehu Sayih Belay ${ }^{*}$ and Tofik Wudad
}

\begin{abstract}
Background: Preeclampsia is leading causes of maternal and perinatal morbidity and mortality worldwide and it is a hypertensive disorder which usually occurs after 20 weeks of gestation. In Ethiopia, according to Ethiopian National Emergency Obstetric and Newborn Care about 10\% of all maternal mortality (direct and indirect) were due to preeclampsia. Despite this condition has adverse effects on the maternal and child health, its prevalence is still significant especially in developing countries including Ethiopia.

Objectives: The aim of the study is to assess the prevalence and associated factors of preeclampsia among pregnant women attending antenatal care at Mettu Karl referral hospital.

Method: The study was conducted at Mettu Karl referral hospital using institutional based cross sectional study design among women whose age was greater or equal to eighteen from March to April 2018. Data were collected from 129 participants by face to face interview technique using structured and pretested questionnaire. Logistic regression analysis was used to identify the factors associated with preeclampsia development.
\end{abstract}

Result: A total of 129 participants were enrolled in the study with the mean age of 25.87 [SD \pm 4.757$]$. Prevalence of preeclampsia among the current pregnant women who attend ANC in Mettu Karl Hospital were 16 (12.4\%) with $95 \% \mathrm{Cl}(7,18)$. Predictor variables like respondents age (AOR $=.009,95 \% \mathrm{Cl}=[.000, .317])$, current multiple pregnancy $(\mathrm{AOR}=.071,95 \% \mathrm{Cl}=[.007, .773])$ and history of diabetes mellitus $(\mathrm{AOR}=.058,95 \% \mathrm{Cl}=[.007-.465])$ were significantly associated with the current preeclampsia.

Conclusion: The finding of this study showed that a considerable proportion of women had preeclampsia. Health seeking behavior towards pregnant women's should be encouraged for both urban and rural residents, which provide a chance to diagnose preeclampsia as early as possible and to prevent the coming complication towards preeclampsia.

Keywords: Factors, Prevalence, Preeclampsia, Pregnant women, Anti-natal care

\footnotetext{
* Correspondence: Alex.sayihalem2018@gmail.com

Department of Nursing, College of Health Sciences, Mizan Tepi University,

P.O. Box 260, Mizan Teferi, Ethiopia
}

(c) The Author(s). 2019 Open Access This article is distributed under the terms of the Creative Commons Attribution 4.0 International License (http://creativecommons.org/licenses/by/4.0/), which permits unrestricted use, distribution, and reproduction in any medium, provided you give appropriate credit to the original author(s) and the source, provide a link to the Creative Commons license, and indicate if changes were made. The Creative Commons Public Domain Dedication waiver (http://creativecommons.org/publicdomain/zero/1.0/) applies to the data made available in this article, unless otherwise stated. 


\section{Introduction}

Preeclampsia is the leading causes of maternal and perinatal morbidity and mortality worldwide and it is a hypertensive disorder which usually occurs after 20 weeks of gestation. It is a rapidly progressive condition characterized by elevated blood pressure and protein in the urine $[1,2]$. It is a cause of severe morbidity, long term disability and death among both mothers and their babies. The risk of maternal death is much more common in settings in which prenatal and intra partum care is not routinely available to pregnant women [3].

Every day in 2015, about 830 women died due to complications of pregnancy and childbirth. Almost all of these deaths occurred in low-resource settings, and most could have been prevented [4]. Pregnancy induced hypertensions like preeclampsia is one of the primary causes of death $[5,6]$. Of the 830 daily maternal deaths, 550 occurred in Sub-Saharan Africa and 180 in Southern Asia, compared to 5 in developed countries. The risk of a woman in a developing country dying from a maternal-related causes during her lifetime is about 33 times higher compared to a woman living in a developed country [7].

The prevalence of preeclampsia in developing countries ranges from 1.8 to $16.7 \%$ [8]. For instance, the prevalence of preeclampsia occurs in $10 \%$ of pregnancies in African women, which is significantly higher than the global average of approximately $2 \%$ [9].

In Ethiopia, the estimate of the maternal mortality ratio for the 7-year period preceding the 2016 Ethiopian demographic health survey (EDHS) is 412 deaths per 100,000 live births; that is, for every 1000 births in Ethiopia, there are about 4 maternal deaths [5].

A 5 year retrospective review in Ambo Hospital found that $12.3 \%$ maternal mortality occurred due to hypertension disorder of pregnancy [10]. Moreover, according to Ethiopian National Emergency Obstetric and Newborn Care (EMONC) $16 \%$ of direct maternal mortality and $10 \%$ of all maternal mortality (direct and indirect) was due to preeclampsia/eclampsia [11].

Despite this condition has adverse effects on the maternal and child health, [12] its prevalence is still significant especially in developing countries including Ethiopia. In general, preeclampsia remains a major problem both in maternal and infants morbidity and mortality. But the risk factors for preeclampsia have not been well documented in Ethiopia. Hence, this study can assess the prevalence and its associated factors of preeclampsia among pregnant women in Mettu Karl Referral hospital, South West Ethiopia.

\section{Methodology}

\section{Study area}

The study was conducted at Mettu Karl referral hospital found in Metu (also Mettu) which is a market town and separate woreda in South West Ethiopia, Oromia region,
Ilu-Ababor Zone. It is located $600 \mathrm{~km}$ from the capital city of Ethiopia, Addis Ababa. Mettu, located in the Illubabor Zone of the Oromia Region along the Sor River, this town has a latitude and longitude of $8^{\circ} 18^{\prime} \mathrm{N} 35^{\circ} 35^{\prime} \mathrm{E}$ and an altitude of $1605 \mathrm{~m}$. This hospital is being given different services for clients referred from health centers around Illubabor. It also gives service for mothers who suffer from fistula at its fistula center. Generally the hospital can give service for around 1.4 million clients. Regarding the delivery information, the average annual number of delivering mothers is estimated to be 3602 .

\section{Study design, period and population}

Institutional based cross sectional study design was conducted among women whose age was greater or equal to eighteen from March to April 2018. Selected pregnant women who gave at least one child birth and those who were above 20 weeks of gestation for current pregnancy were included.

\section{Sample size determination}

The sample size was determined using single population proportion formula using the following assumptions; the magnitude of preeclampsia, which is $8.4 \%$ in Dessie referral hospital [13], confidence interval 95\%, the margin of error $\mathrm{d}=0.05, \mathrm{Za} / 2=1.96$ and with $10 \%$ non-respondent rate the final sample size was 129 .

\section{Sampling procedure and data collection instrument}

First, we obtained the annual report of the pregnant mothers with gestational age of greater than 20 weeks in ANC then we divide by 12 to get the flow of pregnant mothers per month. Then finally we found about 139 pregnant mothers who come for ANC follow up. Then the total sample size required was collected consecutively within the given period.

The questionnaire is adopted and modified from reviewing different literatures and scientific facts [1,13-16]. Data were collected by face to face interview technique using structured and pretested questionnaire. Medical records were also reviewed for some clinical and laboratory results, including proteinuria and blood pressure measurement.

\section{Data quality control}

A questionnaire was first prepared in English and then translated to national language (Amharic) and was translated back to English by another individual in order to check and maintain its consistency.

After necessary modifications and correction was made and ensured its reliability by the pre-test, the actual data were collected by four midwife nurses. To maintain the quality of the data the 3 days of training was given for the data collectors. Questionnaires which were collected were checked for its completeness and 
consistency of the filled questionnaires on a daily basis. Blood pressure was taken under standard operating procedure by two data collectors for each participant, to keep its reliability of measurement and to correctly diagnose preeclampsia. Current multiple pregnancy was also confirmed by both the physical examination and ultrasound evaluation. The medical registration numbers of the participants who were involved in the study were recorded on a separate sheet to avoid repeated recruitment of the study participants who come for the next visit.

In addition, the data were thoroughly cleaned and carefully entered into computer for beginning of analysis.

\section{Operational definition}

Gestational age: is calculated from the last normal menstrual period (LNMP) and for those women who didn't recall their last menstrual period, fundal height and/or ultrasound result was used.

Gravidity: the total number of pregnancies, including abortion, ectopic pregnancy and any other pregnancies documented on the chart.

Parity: the number of deliveries after 28 weeks of gestation including IUFD and still birth documented in the chart.

Pre-eclampsia: denotes for women with blood pressure of $\geq 140 \mathrm{mmHg}$ systolic or $\geq 90 \mathrm{mmHg}$ diastolic on two separate readings taken at least four to six hours apart after 20 weeks gestation in an individual with previously normal blood pressure and proteinuria in pregnancy $[1,17]$.

Proteinuria: is assessed using the urine dipstick method. Those women levels of +1 and above are classified as having proteinuria.

\section{Data processing and analysis}

Data was entered using epi-data manager and exported, cleaned and analyzed using statistical package for social science (SPSS) version 21.

The multicollinarity between the variables were checked and there were no interaction among independent variables. We also checked the linear relationship between the continuous variable age and its logit transformation and finally we found that there was no linear relationship. As a result the independent variable age was categorized. Each independent/ predictor variables and outcome variable was investigated using bivariate logistic regression model. The independent variables that were statistically significant with $p$ value $<0.05$ and $95 \% \mathrm{CI}$ at bivariate analysis was included in multivariate logistic regression model using enter method to control for potential confounder variables. Finally, variables (age, current multiple pregnancy and participant history of diabetic mellitus) with $p$ value $<0.05$ were taken as strong predictor variables of preeclampsia.

\section{Ethical consideration}

Approval letter was obtained from Mizan-Tepi University, college of medicine and health sciences. The necessary information regarding to the importance of the study was addressed for each participant. Written consent was taken from each participant and their confidentiality and privacy was maintained.

\section{Result}

\section{Socio-demographic characteristics of the study} participants

A total of 129 participants who come for ANC follow up in Mettu Karl hospital were enrolled in the study with the $100 \%$ response rate. The mean age of the participants were 25.87 [SD \pm 4.757 ]. About $47(36.4 \%)$ and $37(28.7 \%)$ of the participants were in the age range of 25-29 and 30-34 respectively.

Majority of the participants, $113(87.6 \%)$ were married and most of them, 46 (35.7\%) were Protestant by religion. More than half of the participants, 74 (57.4\%) were housewife by their occupational status, whereas $18(14.0 \%)$ of the respondents ever had more than one partner (Table 1).

\section{Obstetrical characteristics of the respondents}

Most of the participants age at first pregnancy, 118 $(91.5 \%)$ were $>=18$. Of the total number of the current pregnancy, 11 (8.5\%) were unintended pregnancy. About 87 (67.4\%) of the participants ever had a history of ANC follow up during previous pregnancy, whereas 13 (10.1\%) of the total participant had a history of abortion (Table 2).

\section{Prevalence of preeclampsia and clinical characteristics of the respondents}

Prevalence of preeclampsia among the current pregnant women who attend ANC at Mettu Karl hospital were 16 (12.4\%) with 95\% CI [7, 18]. About 124 (96.1\%) of the participants were ever heard about dander sign. Among the total participants, 13 (10.1\%) of them had a family history of chronic hypertension, whereas 7 (5.4\%) of the total participants had a family history of kidney diseases (Table 3 ).

\section{Factors associated with preeclampsia}

On bivariate analysis, different independent variables like; age, residence, ever had more than one partner, current multiple pregnancy, family history of diabetes mellitus, the participant history of diabetes mellitus, the participant history of kidney disease, ever had a history of ANC follow up during previous pregnancy and parity were significantly associated with mothers with preeclampsia. But after adjusting for the possible confounding factors using multivariate analysis, variables like age, current multiple pregnancy and participant history of diabetic mellitus were become good independent predictor variables for preeclampsia. 
Table 1 Socio demographic characteristics of the respondents $(n=129)$, Mettu Karl Referral Hospital, South West Ethiopia, 2018

\begin{tabular}{lll}
\hline Variables & Frequency & $\%$ \\
\hline
\end{tabular}

Place of residence

$\begin{array}{lll}\text { Rural } & 53 & 41.1 \\ \text { Urban } & 76 & 58.9\end{array}$

Age of respondents

$\begin{array}{ll}<=24 & 30 \\ 25-29 & 47 \\ 30-34 & 37 \\ >=35 & 15 \\ \text { Mean } \pm \text { SD } & 25.87 \pm 4.757\end{array}$

Marital status

Married

Single

Divorced

Widowed

Separated

Religion

$\begin{array}{ll}\text { Muslim } & 37 \\ \text { Orthodox } & 45 \\ \text { Protestant } & 46 \\ \text { Catholic } & 1 \\ \text { Ethnicity } & \end{array}$

Ethnicity

Oromo

Amhara

Tigre

Other $^{\mathrm{a}}$

Respondent's educational status

Unable to write and read

Able to read and write

Primary

Secondary

Certificate and above

Respondent's occupational status

House wife

Governmental Employee

Merchant

Student

Husband occupational status

Farmer

Governmental employee

NGO employee

Merchant

Husband educational status

Unable to write and read
41.1

23.3

36.4

28.7

11.6

$25.87 \pm 4.757$

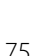

75.2

16.3

5.4

3.1

4
Table 1 Socio demographic characteristics of the respondents ( $n=129)$, Mettu Karl Referral Hospital, South West Ethiopia, 2018 (Continued)

\begin{tabular}{lll}
\hline Variables & Frequency & $\%$ \\
\hline Able to read and write & 29 & 22.5 \\
Primary & 24 & 18.6 \\
Secondary & 25 & 19.4 \\
Certificate and above & 24 & 18.6 \\
Ever had more than one partner & & \\
Yes & 18 & 14.0 \\
No & 111 & 86.0 \\
\hline indicates that Gurage and Sheka & &
\end{tabular}

Respondents whose age were $<=24$ were less likely to be preeclamptic women than those whose age were $>=35(\mathrm{AOR}=.009,95 \% \mathrm{CI}=[.000, .317])$. Participants who had no current multiple pregnancy were less likely to be preeclamptic women than those women with current multiple pregnancy $(\mathrm{AOR}=\mathbf{. 0 7 1}$, $95 \% \mathrm{CI}=[.007, .773])$. Participant with no history of diabetes mellitus were less likely to be preeclamptic than those with a history of diabetes mellitus (AOR $=\mathbf{. 0 5 8}, 95 \%$ $\mathrm{CI}=[.007-.465])($ Table 4$)$.

Table 2 Obstetrical characteristic of respondents, Mettu Karl Referral Hospital, South West Ethiopia, 2018

\begin{tabular}{lll}
\hline Variables & Frequency & $\%$ \\
\hline Age at first pregnancy & 11 & 8.5 \\
$<18$ & 118 & 91.5 \\
$>=18$ & & \\
Status of current pregnancy & & 91.5 \\
Intended & 118 & 8.5 \\
Unintended & 11 & \\
Presence of current multiple pregnancy & 11.6 \\
Yes & 15 & 88.4 \\
No & 114 & \\
Gravidity & & 33.3 \\
$<=2$ & 43 & 66.7 \\
$>2$ & 86 & 14.7 \\
Parity & & 37.2 \\
$<2$ & 19 & 48.1 \\
$2-3$ & 48 & 62
\end{tabular}

Ever had history of ANC follow up during previous pregnancy

$\begin{array}{lll}\text { Yes } & 87 & 67.4 \\ \text { No } & 42 & 32.6\end{array}$

History of abortion

$\begin{array}{lll}\text { Yes } & 13 & 10.1\end{array}$

$\begin{array}{lll}\text { No } & 116 & 89.9\end{array}$ 
Table 3 Prevalence of preeclampsia and clinical characteristics of the respondents, Mettu Karl Referral Hospital, South West Ethiopia, 2018

\begin{tabular}{|c|c|c|}
\hline Variables & Frequency & $\%$ \\
\hline \multicolumn{3}{|c|}{ Mother with preeclampsia } \\
\hline No & 113 & 87.6 \\
\hline Yes & 16 & 12.4 \\
\hline \multicolumn{3}{|c|}{ Woman's BP measurement at time of diagnosis } \\
\hline$<140 / 90$ & 108 & 83.7 \\
\hline $140 / 90-160 / 110$ & 16 & 12.4 \\
\hline$>=160 / 110$ & 5 & 3.9 \\
\hline \multicolumn{3}{|c|}{ Ever heard about danger sign } \\
\hline Yes & 124 & 96.1 \\
\hline No & 5 & 3.9 \\
\hline \multicolumn{3}{|c|}{$\begin{array}{l}\text { Utilization of health facility for other health problem during curren } \\
\text { pregnancy }\end{array}$} \\
\hline Yes & 60 & 46.5 \\
\hline No & 69 & 53.5 \\
\hline \multicolumn{3}{|c|}{ History of chronic hypertension } \\
\hline Yes & 6 & 4.7 \\
\hline No & 123 & 95.3 \\
\hline \multicolumn{3}{|c|}{ Family history of chronic hypertension } \\
\hline Yes & 13 & 10.1 \\
\hline No & 116 & 89.9 \\
\hline \multicolumn{3}{|c|}{ Family history of pregnancy induced hypertension } \\
\hline Yes & 3 & 2.3 \\
\hline No & 126 & 97.7 \\
\hline \multicolumn{3}{|c|}{ Family history of diabetes mellitus } \\
\hline Yes & 7 & 5.4 \\
\hline No & 122 & 94.6 \\
\hline \multicolumn{3}{|c|}{ History of kidney disease } \\
\hline Yes & 42 & 32.6 \\
\hline No & 87 & 67.4 \\
\hline \multicolumn{3}{|c|}{ Family history of kidney diseases } \\
\hline Yes & 7 & 5.4 \\
\hline No & 122 & 94.6 \\
\hline
\end{tabular}

\section{Discussion}

This institutional based cross sectional study was conducted in Mettu Karl referral hospital to identify the prevalence of preeclampsia and its associated factors.

In addition to this, the finding of this study will have a significant role towards overcoming the problems associated with preeclampsia and which in turn helps to decrease the maternal morbidity and mortality associated with preeclampsia.

Hence, in this study, we found that the prevalence of preeclampsia among the current pregnant women who attend ANC at Mettu Karl hospital were 16(12.4\%).
This study finding was found to be high as compared with the studies conducted in different areas where it was found to be $3 \%$ in Norway [18], 2.31\% in German in 2006 [19], 9.5\% in Mustafa hospital of Ilam in the west of Iran [20] and $0.17 \%$ in Shiraz Southern Iran [21] and $4.8 \%$ in Brazzaville Teaching Hospital in the demographic republic of Congo DRC [22]. In comparison with the other studies conducted in different areas of the world, it was also found to be high as compared with the studies conducted in different parts of Ethiopia, where $8.4 \%$ in Dessie referral hospital [13] and 2.23\% in Dilla [16]. This discrepancy might be due to the fact that there is a difference in study setting, socio-economical difference, methodological difference and a difference in time duration. For instance, in Norway the study was conducted for 40 years secular trends in epidemiology of preeclampsia and in DRC a prospective and transversal study was implemented where it was not conducted in this study.

In contrast to the other study, this study finding was found to be lower compared with the studies conducted in different areas where $16 \%$ in Nigeria [23] and 51.9\% in Jimma University Specialized Hospital [24]. Theses difference might be attributed to the difference in socio-demographic and methodological difference. For example, large numbers of study participants where 1257 participants were included in the study in Nigeria but 129 study participants were included in this study. In addition to this, in Jimma the prevalence revealed that it was among those participants with PIH excluding participants with no PIH whereas in this study the prevalence showed among all participants.

Different independent predictor variables for preeclampsia were identified in this study.

In this study, maternal age was found to be significantly associated with preeclampsia. Respondents whose age were less than or equal to 24 were less likely to be preeclamptic women than those whose age were greater than or equal to 35. This is congruent with the study conducted in Germany [19], in Pakistan [25], in Tehran, Iran [26] and in Ethiopia, Desse [13]. This could be explained as the age increases, arteries will be clogged, which could lead to serious repercussions such as strokes or heart attacks. As the age increased, there will be poor diet or lack of exercise and ability of the body to process dietary salt, which in turn causes reduced elasticity of the blood vessels and finally causes the women to be hypertensive [27].

Multiple gestation was also significantly associated with preeclampsia. In this study, respondents who had no current multiple pregnancies were less likely to be preeclamptic than those women with current multiple pregnancy. This study finding was consistent with the studies conducted in Egypt [28], and in Ireland [29]. This might be due to the fact that, preeclampsia is 
Table 4 Factors associated with preeclampsia among women attending antenatal clinic at Mettu Karl referral Hospital, 2018

\begin{tabular}{|c|c|c|c|c|c|}
\hline \multirow[t]{2}{*}{ Variables } & \multicolumn{2}{|c|}{ Mother with preeclampsia } & \multirow[t]{2}{*}{ COR $(95 \%$ C. I) } & \multirow[t]{2}{*}{ AOR (95\% C.I) } & \multirow[b]{2}{*}{$P$-values } \\
\hline & No $(n)$ & Yes $(n)$ & & & \\
\hline \multicolumn{6}{|l|}{ Age } \\
\hline$<=24$ & 29 & 1 & $.039(.004-.369)$ & $.009(.000-.317)^{*}$ & .010 \\
\hline $25-29$ & 42 & 5 & $.136(.034-.538)$ & $.362(.030-4.332)$ & .423 \\
\hline $30-34$ & 34 & 3 & $.101(.021-.478)$ & $.136(.009-2.020)$ & .147 \\
\hline$>=35$ & 8 & 7 & $1.00^{\mathrm{a}}$ & $1.00^{\mathrm{a}}$ & \\
\hline \multicolumn{6}{|l|}{ Residence } \\
\hline Rural & 40 & 13 & $7.908(2.127-29.405)$ & $5.043(.670-37.96)$ & .116 \\
\hline Urban & 73 & 3 & $1.00^{\mathrm{a}}$ & $1.00^{\mathrm{a}}$ & \\
\hline \multicolumn{6}{|c|}{ Ever had more than one partner } \\
\hline Yes & 11 & 7 & $7.212(2.245-23.174)$ & 1.57(.149-16.51) & .707 \\
\hline No & 102 & 9 & $1.00^{\mathrm{a}}$ & $1.00^{\mathrm{a}}$ & \\
\hline \multicolumn{6}{|c|}{ Current multiple pregnancy } \\
\hline Yes & 8 & 7 & $1.00^{\mathrm{a}}$ & $1.00^{\mathrm{a}}$ & \\
\hline No & 105 & 9 & $.098(.029-.332)$ & $.071(.007-.773)^{*}$ & .030 \\
\hline \multicolumn{6}{|c|}{ Family history of diabetic mellitus } \\
\hline Yes & 4 & 3 & $6.288(1.265-31.26)$ & 1.63(.091-29.35) & .741 \\
\hline No & 109 & 13 & $1.00^{\mathrm{a}}$ & $1.00^{\mathrm{a}}$ & \\
\hline \multicolumn{6}{|c|}{ Participant history of diabetes mellitus } \\
\hline Yes & 13 & 11 & $1.00^{\mathrm{a}}$ & $1.00^{\mathrm{a}}$ & \\
\hline No & 100 & 5 & $.059(.018-.197)$ & $.058(.007-.465)^{*}$ & .007 \\
\hline \multicolumn{6}{|c|}{ History of kidney disease } \\
\hline Yes & 32 & 10 & $4.219(1.416-12.57)$ & $1.345(.183-9.89)$ & .771 \\
\hline No & 81 & 6 & $1.00^{\mathrm{a}}$ & $1.00^{\mathrm{a}}$ & \\
\hline \multicolumn{6}{|c|}{ Ever had history of ANC follow up during previous pregnancy } \\
\hline Yes & 81 & 6 & $.237(.080-.706)$ & $.260(.021-3.151)$ & .290 \\
\hline No & 32 & 10 & $1.00^{\mathrm{a}}$ & $1.00^{\mathrm{a}}$ & \\
\hline \multicolumn{6}{|l|}{ Parity } \\
\hline$<2$ & 16 & 3 & $.869(.216-3.507)$ & $2.55(.245-26.56)$ & .434 \\
\hline $2-3$ & 46 & 2 & $.202(.042-.958)$ & $.204(.017-2.407)$ & .207 \\
\hline$>=4$ & 51 & 11 & $1.00^{\mathrm{a}}$ & $1.00^{\mathrm{a}}$ & \\
\hline
\end{tabular}

${ }^{*}$ Adjusted for all significant variables $p<0.05$

$a=$ Reference Category

associated with the presence of soluble substance which is a circulating antiangiogenic molecule of placental origin, plays a central role in preeclampsia by antagonizing placental growth factor (PIGF) and vascular endothelial growth factor signaling in the maternal vasculature [30].

History of diabetes mellitus was also another independent predictor variable for preeclampsia. Women with no history of diabetes mellitus were less likely to be preeclamptic than those with a history of diabetes mellitus. This finding is in line with the studies conducted in Sweden [31], in Ireland [29] and in Germany [32]. This might be explained by that diabetes is a disease in which the blood glucose, or blood sugar, levels are too high which will cause narrowing of blood vessels and interfere with the normal physiological response during pregnancy.

\section{Conclusion}

The prevalence of preeclampsia in this study was higher than other similar studies. Predictor variables like; the age of participant, having multiple pregnancies and having a history of diabetes were factors associated with preeclampsia. Therefore, health seeking behavior towards pregnant women's should be encouraged for both urban and rural residents, which provide a chance to diagnose preeclampsia as early as possible and to prevent the coming complication towards preeclampsia. 


\section{Limitation of study}

Even though this study contributes as an input for the policy makers towards the decrement of the maternal morbidity and mortality, it has its own limitations. First, since cross-sectional study design was implemented, it can't establish cause effect relationship between the predictor variables and dependent variables. Second, recall bias might be expected for the last menstrual period. Third, because of resource limitation, we only incorporated one hospital as study area. Finally, since the study was institutional based study, the result will not be generalizable to the general population of the catchment area.

\section{Abbreviation}

ANC: Ante natal care; BP: Blood pressure; DBP: Diastolic blood pressure; EDHS: Ethiopian demographic health survey; EMONC: Emergency obstetric and newborn care; LNMP: Last normal menstrual period; mmHg: Millimeter of mercury; PIH: Pregnancy induced hypertension; SBP: Systolic blood pressure

\section{Acknowledgements}

We are grateful to Mizan Tepi University for technical support. We are also very indebted to extend our gratitude to the respondents who offered their time to participate in this study. The last but not the least, we would like to thank Mr. Mintesinot Elias, Mr. Akalat Sefiwu and Mrs. Merartu Gadisa for their unreserved help during proposal development and technical support during data collection time.

\section{Funding}

No funding source.

\section{Availability of data and materials}

The data sets used and/or analyzed during the current study are available from the corresponding author on reasonable request.

\section{Authors' contributions}

AS conceptualized the paper, searched the literature, constructed the methodology and trained data collectors and wrote the results, discussion and conclusion sections. He also critically analyzed and reviewed the results and wrote the manuscript draft. TW also searched the literature, and trained data collectors. He also critically analyzed, reviewed and edited the results, discussion, conclusion and recommendation sections. All authors critically analyzed, reviewed and edited the results, discussion, conclusion and recommendation sections. All authors also read and approved the final manuscript.

\section{Ethics approval and consent to participate}

Ethical clearance was obtained from the research directorate office of Mizan Tepi University. After explaining the objectives of the study, written consent was obtained from each study participant. Interviews with study participants were conducted with strict privacy and assuring confidentiality.

\section{Consent for publication}

Not applicable.

\section{Competing interests}

The authors declare that they have no competing interests.

\section{Publisher's Note}

Springer Nature remains neutral with regard to jurisdictional claims in published maps and institutional affiliations.
Received: 10 December 2018 Accepted: 10 May 2019

Published online: 01 July 2019

\section{References}

1. Davey D, MacGillivray I. The classification and definition of the hypertensive disorders of pregnancy: proposals submitted to the international society for the study of hypertension in pregnancy. Clin Exp Hypertens B. 1986;5(1):97-133.

2. Gynecologists $\mathrm{A}$. of $\mathrm{O}$ and, Pregnancy TF on $\mathrm{H}$ in. Hypertension in pregnancy report of the American College of Obstetricians and Gynecologists' task force on. Hypertens Pregnancy Obs Gynecol. 2013;122: 1122-31.

3. Goldenberg RL, Rouse DJ. Prevention of premature birth. N Engl J Med. 1998;339(5):313-20.

4. Alkema L, Chou D, Hogan D, Zhang S, Moller A-B, Gemmill A, et al. Global, regional, and national levels and trends in maternal mortality between 1990 and 2015, with scenario-based projections to 2030: a systematic analysis by the UN maternal mortality estimation inter-agency group. Lancet. 2016; 387(10017):462-74.

5. Ethiopia - Demographic and Health Survey 2016 [ it appeared on 15 Oct 2018 10:26:16 GMT]; Available from: http://microdata.worldbank.org/index. php/catalog/2886

6. Say L, Chou D, Gemmill A, Tunçalp Ö, Moller A-B, Daniels J, et al. Global causes of maternal death: a WHO systematic analysis. Lancet Glob Health. 2014;2(6):e323-e33.

7. WHO U. UNFPA, World Bank Group and the United Nations Population Division. Trends in maternal mortality: 1990 to 2015. Estimates by WHO, UNICEF. UNFPA. Geneva: World Bank Group and the United Nations population division; 2015.

8. Lakew Y, Reda AA, Tamene H, Benedict S, Deribe K. Geographical variation and factors influencing modern contraceptive use among married women in Ethiopia: evidence from a national population based survey. Reprod Health. 2013;10(1):52.

9. Nakimuli A, Chazara O, Byamugisha J, Elliott AM, Kaleebu P, Mirembe F, et al. Pregnancy, parturition and preeclampsia in women of African ancestry. Am J Obstet Gynecol. 2014;210(6):510-20 e1.

10. Garomssa H, Dwivedi A. Maternal mortality in ambo hospital: a five year retrospective review. Ethiop J Reprod Health. 2008;2:1.

11. Gaym A, Bailey P, Pearson L, Admasu K, Gebrehiwot Y. Disease burden due to pre-eclampsia/eclampsia and the Ethiopian health system's response. Int J Gynecol Obstet. 2011;115(1):112-6.

12. Moussa HN, Arian SE, Sibai BM. Management of hypertensive disorders in pregnancy. Women's Health. 2014;10(4):385-404.

13. Tessema GA, Tekeste A, Ayele TA. Preeclampsia and associated factors among pregnant women attending antenatal care in Dessie referral hospital, Northeast Ethiopia: a hospital-based study. BMC Pregnancy Childbirth. 2015;15(1):73.

14. Seyom E, Abera M, Tesfaye M, Fentahun N. Maternal and fetal outcome of pregnancy related hypertension in Mettu Karl referral hospital, Ethiopia. J Ovarian Res. 2015;8(1):10.

15. Grum T, Seifu A, Abay M, Angesom T, Tsegay L. Determinants of preeclampsia/eclampsia among women attending delivery Services in Selected Public Hospitals of Addis Ababa, Ethiopia: a case control study. BMC Pregnancy Childbirth. 2017;17(1):307.

16. Vata PK, Chauhan NM, Nallathambi A, Hussein F. Assessment of prevalence of preeclampsia from Dilla region of Ethiopia. BMC Res Notes. 2015;8(1):816.

17. Kintiraki E, Papakatsika S, Kotronis G, Goulis DG, Kotsis V. Pregnancy-induced hypertension. Hormones. 2015;14(2):211-23.

18. Klungsøyr K, Morken NH, Irgens L, Vollset SE, Skjærven R. Secular trends in the epidemiology of pre-eclampsia throughout 40 years in Norway: prevalence, risk factors and perinatal survival. Paediatr Perinat Epidemiol. 2012;26(3):190-8.

19. Schneider S, Freerksen N, Maul H, Roehrig S, Fischer B, Hoeft B. Risk groups and maternal-neonatal complications of preeclampsia-current results from the national German perinatal quality registry. J Perinat Med. 2011;39(3): 257-65.

20. Direkvand-Moghadam A, Khosravi A, Sayehmiri K. Predictive factors for preeclampsia in pregnant women: a unvariate and multivariate logistic regression analysis. Acta Biochim Pol. 2012;59(4):674.

21. Zibaeenezhad MJ, Ghodsi M, Arab P, Gholzom N. The prevalence of hypertensive disorders of pregnancy in Shiraz, Southern Iran; 2010. 
22. Kimbally K, Barassoumbi H, Buambo S, Gombet T, Kibeke P, Monabeka H, et al. Arterial hypertension: epidemiological aspects and risk factors on pregnant and delivered woman. Dakar Med. 2007;52(2):148-52.

23. Guerrier G, Oluyide B, Keramarou M, Grais RF. Factors associated with severe preeclampsia and eclampsia in Jahun, Nigeria. Int J Women's Health. 2013;5:509.

24. Wolde Z, Segni H, Woldie M. Hypertensive disorders of pregnancy in Jimma University specialized hospital. Ethiop J Health Sci. 2011;21:3.

25. Shamsi U, Saleem S, Nishter N, Ameen A. Epidemiology and risk factors of preeclampsia; an overview of observational studies. Al Ameen J Med Sci. 2013;6(4):292-300.

26. Kashanian M, Baradaran HR, Bahasadri S, Alimohammadi R. Risk factors for pre-eclampsia: a study in Tehran, Iran. Arc Iran Med. 2011;14(6):412.

27. Sandberg Yossy. Why does blood pressure rise with age? March 30, 2016; Available from: https://www.resperate.com/blog/hypertension/facts/causesrisks/blood-pressure-rise-age.

28. El-Moselhy EA, Khalifa HO, Amer SM, Mohammad KI, El-Aal HMA. Risk factors and impacts of pre-eclampsia: an epidemiological study among pregnant mothers in Cairo, Egypt. J Am Sci. 2011;7(5):311-23.

29. English FA, Kenny LC, McCarthy FP. Risk factors and effective management of preeclampsia. Integr Blood Press Control. 2015;8:7.

30. Bdolah Y, Lam C, Rajakumar A, Shivalingappa V, Mutter W, Sachs BP, et al. Twin pregnancy and the risk of preeclampsia: bigger placenta or relative ischemia? Am J Obstet Gynecol. 2008;198(4):428. e1-6.

31. Östlund I, Haglund B, Hanson U. Gestational diabetes and preeclampsia. Eur J Obstet Gynecol Reprod Biol. 2004;113(1):12-6.

32. Schneider S, Freerksen N, Röhrig S, Hoeft B, Maul H. Gestational diabetes and preeclampsia-similar risk factor profiles? Early Hum Dev. 2012;88(3):179-84.

Ready to submit your research? Choose BMC and benefit from:

- fast, convenient online submission

- thorough peer review by experienced researchers in your field

- rapid publication on acceptance

- support for research data, including large and complex data types

- gold Open Access which fosters wider collaboration and increased citations

- maximum visibility for your research: over $100 \mathrm{M}$ website views per year

At $\mathrm{BMC}$, research is always in progress.

Learn more biomedcentral.com/submissions 